\title{
Ontogeny of swimming speed in larvae of pelagic-spawning, tropical, marine fishes
}

\author{
Jeffrey M. Leis ${ }^{1,3, *}$, Amanda C. Hay ${ }^{1}$, Matthew M. Lockett ${ }^{1}$, Jeng-Ping Chen ${ }^{2}$, \\ Lee-Shing Fang ${ }^{2,4}$ \\ ${ }^{1}$ Ichthyology, Australian Museum, 6 College Street, Sydney, New South Wales 2010, Australia \\ ${ }^{2}$ National Museum of Marine Biology and Aquarium, 2 Houwan Road, Checheng, Pingtung 944, Taiwan \\ ${ }^{3}$ School of Biological Earth and Environmental Sciences, University of New South Wales, Sydney, New South Wales 2052, \\ Australia \\ ${ }^{4}$ Present address: Department of Sport, Health and Leisure, Cheng Shiu University, 840 Chengcing Road, Niaosong hsiang, \\ Kaohsiung County 83347, Taiwan
}

\begin{abstract}
During the pelagic larval phase of teleost fishes, the larvae are subject to dispersal by currents. Dispersal trajectories can be substantially modified if the larvae have sufficient swimming abilities, so it is important to document how swimming ability develops during the pelagic larval phase. We used reared larvae (4 to $29 \mathrm{~mm}$ standard length) from commercial aquaculture farms in Taiwan to measure the development of swimming ability (critical speed, $U_{\text {crit }}$ ) in larvae of 9 species (from 7 families) of Indo-Pacific coral reef and coastal fishes that hatch from pelagic eggs: Trachinotus blochii (Carangidae - jacks), Chanos chanos (Chanidae - milkfish), Platax teira (Ephippidae batfishes), Leiognathus equulus (Leiognathidae - ponyfishes), Lutjanus malabaricus (Lutjanidae snappers), Eleutheronema tetradactylum (Polynemidae - threadfins), and Epinephelus coioides, E. fuscoguttatus and E. malabaricus (Serranidae - groupers). Mean critical swimming speeds increased from $<5 \mathrm{~cm} \mathrm{~s}^{-1}$ in the smallest larvae to a maximum of $47 \mathrm{~cm} \mathrm{~s}^{-1}$ in settlement stage larvae, with the increase in speed by the time of settlement ranging from 6- to 100-fold. Increase in swimming speed was more strongly correlated with size of larvae $\left(R^{2}=0.38\right.$ to $\left.0.93, p<0.005\right)$ than with age (correlation with age was absent in 3 species and explained 10 to $43 \%$ less variation than did size in the others). The relationship between speed and size was linear. In 6 species (T. blochii, C. chanos, L. malabaricus and the 3 Epinephelus species) speed increased at a rate of 2.1 to $2.6 \mathrm{~cm} \mathrm{~s}^{-1}$ for each $1 \mathrm{~mm}$ increase in size. Three species ( $P$. teira, L. equulus and E. tetradactylum) had a significantly slower rate of increase of 1.3 to $1.7 \mathrm{~cm} \mathrm{~s}^{-1}$ for each $1 \mathrm{~mm}$ increase in size. On average, the best performers in each $1 \mathrm{~mm}$ size increment were 1.5 to $7.3 \mathrm{~cm} \mathrm{~s}^{-1}$ faster than mean performers, depending on species. Throughout development the vast majority of mean length-specific speeds were 10 to 20 body lengths (BL) $\mathrm{s}^{-1}$, and length-specific speed increased significantly with size in 6 species. Maximum length-specific speeds for each species reached 18 to $31 \mathrm{BL} \mathrm{s}^{-1}$. Although the ontogeny of swimming speed varies among species of tropical marine fishes, over similar size ranges, larvae that hatch from pelagic eggs have swimming abilities similar to those reported for larvae that hatch from demersal eggs.
\end{abstract}

KEY WORDS: Marine fishes - Pelagic eggs · Pelagic larvae · Swimming speed • Ontogeny • Dispersal $\cdot$ Serranidae $\cdot$ Lutjanidae $\cdot$ Carangidae $\cdot$ Chanidae

\section{INTRODUCTION}

Recently, it has become apparent that the swimming abilities of marine fish larvae, at least those of perciform species, are considerable (Leis 2006). As they approach the settlement stage, larvae of many species can swim at speeds similar to those of the ambient currents in which they conduct the pelagic portion of their life history (Fisher 2005). This capacity provides larvae with the ability to strongly influence their dispersal trajectories. Therefore, knowledge of the swimming abilities of larvae is of more than academic interest as 
numerical biophysical models require good measures of swimming ability if they are to realistically predict dispersal outcomes (Cowen et al. 2006, Leis 2007).

Most recent estimates of swimming ability of marine fish larvae have been made with a laboratory method called critical speed ( $U_{\text {crit }}$ (Brett 1964) that uses a raceway and incremental increases in speed until the larvae can no longer maintain position (Stobutzki \& Bellwood 1994, Fisher et al. 2000, 2005, Fisher 2005, Leis \& Fisher 2006). The $U_{\text {crit }}$ is a convenient standard method of measuring potential swimming ability and is, therefore, ideal for comparing the performance of different species or developmental stages of fish. Measurements of $U_{\text {crit }}$ are now available for the larvae of a wide variety of mostly tropical, perciform fish species. However, the vast majority of these data are only from the late settlement-stage larvae of these species (Fisher 2005, Fisher et al. 2005, Leis \& Fisher 2006), whereas biophysical dispersal models require information on swimming ability throughout the pelagic larval phase (Leis 2007). At present, $U_{\text {crit }}$ data across a wide range of developmental stages are available for only 8 species of 6 families of marine fishes (Fisher et al. 2000, Clark et al. 2005, Leis et al. 2006a): 2 coral-reef pomacentrids, one coral-reef apogonid, one reef-associated carangid, 2 warm-temperate sparids, a warm-temperate sciaenid and a warm-temperate estuarine percicithyid. In addition, Fisher (2005) presented 'normalised' larval swimming speed data on 2 other pomacentrids and an apogonid, and although these had performance similar to their confamilials, the actual speed-at-age data were not included). The pomacentrids and apogonids are small fishes that spawn non-pelagic eggs, whereas the other 5 species consist of moderate to large fishes that spawn pelagic eggs. In all these species, larvae settle at a relatively small size (8 to $13 \mathrm{~mm}$ standard length, except the pelagic carangid, which does not settle) and have relatively direct development with few larval specializations (Neira et al. 1998, Leis \& Carson-Ewart 2004). As valuable as these data are, the vast diversity of marine teleost fishes is not well represented by these 8 species, and many of the families of most interest to ecologists and managers are not included.

We sought to expand the taxonomic coverage of ontogenetic $U_{\text {crit }}$ data by studying a number of marine species common in the aquaculture industry in Taiwan (Yu 2002). Working from the National Museum of Marine Biology and Aquarium (NMMBA, Pingtung, Taiwan), we were able to obtain quantitative data on the ontogenetic increase in swimming ability of 9 species in 7 families (Table 1, Fig. 1). These include species from a variety of habitats and of considerable commercial and ecological interest. None of the genera we studied here, and only one of the families, had previously been studied in this manner. This more than doubles the species for which the ontogeny of $U_{\text {crit }}$ swimming performance in the larvae is known and extends such measurements to species that settle at sizes up to ca. $25 \mathrm{~mm}$ standard length (SL). The species studied here (Table 1, Fig. 1) include one gonorynchiform species (Chanos chanos) and 8 perciform fishes. The

Table 1. Study species and characteristics. Adult habitat and settlement size information from Bagarinao (1991), Doi et al. (1991), Kohno et al. (1993), Leu et al. (2005), Australian Museum fish database and authors' unpublished data. $N$ is number of specimens for which $U_{\text {crit }}$ was measured (and the number in parentheses for which age was known). Cohorts refers to the number of separate groups of larvae studied; $d=$ no. of days during which $U_{\text {crit }}$ was measured. nd = no data available

\begin{tabular}{|c|c|c|c|c|c|}
\hline Family and species & Adult habitat & $\begin{array}{l}\text { Settlement } \\
\text { size } \\
(\mathrm{mm}, \mathrm{S}\end{array}$ & $\begin{array}{l}U_{\text {crit }} \\
\text { size } \\
\text { SL) }\end{array}$ & $\begin{array}{c}N \\
\text { (with } \\
\text { age) }\end{array}$ & $\begin{array}{c}\text { Cohorts } \\
\text { (d) }\end{array}$ \\
\hline \multicolumn{6}{|l|}{ Carangidae } \\
\hline Trachinotus blochii & Inshore pelagic & nd & $4-6$ & $19(19)$ & $1(2)$ \\
\hline \multicolumn{6}{|l|}{ Chanidae } \\
\hline Chanos chanos & Inshore and estuarine pelagic & 14 & $6-13$ & $43(35)$ & $3(5)$ \\
\hline \multicolumn{6}{|l|}{ Ephippidae } \\
\hline Platax teira & Coral reefs & 30 & $4-11$ & $44(24)$ & $2(4)$ \\
\hline \multicolumn{6}{|l|}{ Leiognathidae } \\
\hline Leiognathus equulus & Soft bottoms in shallow coastal waters and estuaries & 15 & $5-16$ & $73(73)$ & $1(8)$ \\
\hline \multicolumn{6}{|l|}{ Lutjanidae } \\
\hline Lutjanus malabaricus & Low relief reefs and banks & 25 & $5-29$ & $49(30)$ & $4(7)$ \\
\hline \multicolumn{6}{|l|}{ Polynemidae } \\
\hline Eleutheronema tetradactylum & Soft bottoms in shallow coastal waters and estuaries & 20 & $7-22$ & $73(53)$ & $5(6)$ \\
\hline \multicolumn{6}{|l|}{ Serranidae } \\
\hline Epinephelus coioides & Inshore coral reefs and estuaries & $20-24$ & $3-19$ & $39(27)$ & $6(7)$ \\
\hline Epinephelus fuscoguttatus & Coral reefs & $20-24$ & $12-27$ & $23(0)$ & $3(4)$ \\
\hline Epinephelus malabaricus & Inshore coral reefs and estuaries & 24 & $3-25$ & $15(9)$ & $2(2)$ \\
\hline
\end{tabular}




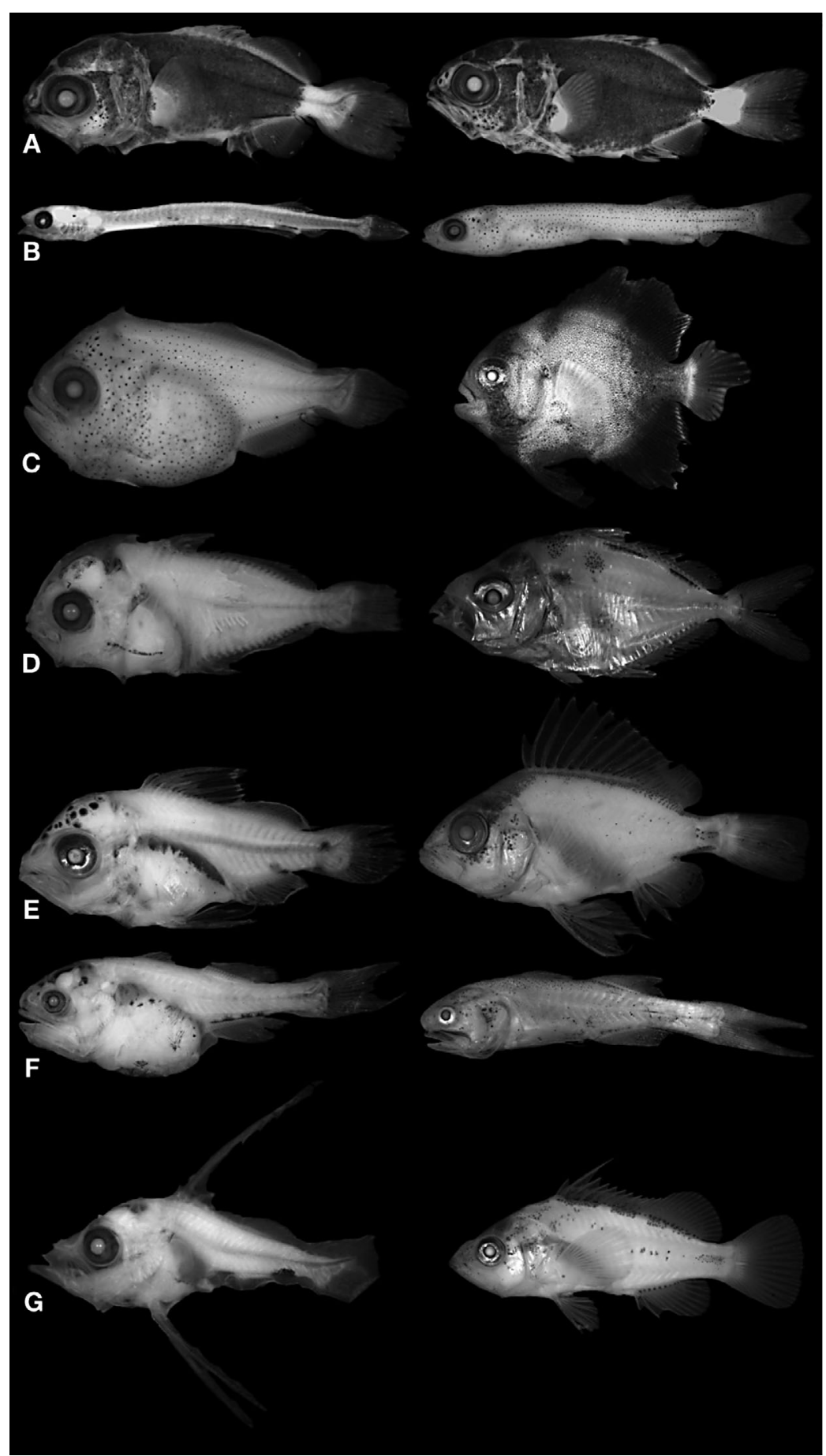

Fig. 1. Larvae of the study species over the range of sizes and developmental stages used to determine swimming speed. For each species, ethanol-preserved individuals near the extremes of sizes ( $\mathrm{mm}, \mathrm{SL})$ studied are shown; left column: small larva; right column: large larva. The images are not to scale. (A) Trachinotus blochii (Carangidae) left, $4 \mathrm{~mm}$; right, $6 \mathrm{~mm}$; (B) Chanos chanos (Chanidae): left, $8 \mathrm{~mm}$; right, $11 \mathrm{~mm}$; (C) Platax teira (Ephippididae): left, $5 \mathrm{~mm}$; right, $11 \mathrm{~mm}$; (D) Leiognathus equulus (Leiognathidae): left, $4.5 \mathrm{~mm}$; right, $14 \mathrm{~mm}$; (E) Lutjanus malabaricus (Lutjanidae): left, $5.5 \mathrm{~mm}$; right, $18.5 \mathrm{~mm}$; (F) Eleutheronema tetradactylum (Polynemidae): left, $7 \mathrm{~mm}$; right, $20 \mathrm{~mm}$; (G) Epinephelus coioides (Serranidae): left 4, mm; right, $20 \mathrm{~mm}$ (E. fuscoguttatus and E. malabaricus are very similar to E. coioides and are not illustrated) chanid and polynemid species have relatively direct development with few larval morphological specializations, whereas the ephippidid, leiognathid, lutjanid and serranid species have highly specialized larvae with morphologies that differ substantially from the settled juveniles. Similarly, the size at which the larvae leave the pelagic environment varies from about 12-13 $\mathrm{mm}$ (Chanidae) to about 20-25 mm (Polymenidae, Lutjanidae, Serranidae).

The goals of this study were to measure the development of swimming ability (defined as $U_{\text {crit }}$ ) across a range of species, families and early life history stages of tropical fishes, and to compare the patterns of swimming development among these and other taxa for which similar data were available. We sought to characterize the ontogeny of swimming in these species (for example, to determine if the increase in speed with size was essentially linear, as has been determined in other species) and to make this information available to investigators who increasingly are including larval behaviour in dispersal models.

\section{MATERIALS AND METHODS}

Larvae were obtained from commercial aquaculture farms in the vicinity of Kaohsiung, southern Taiwan, in May 2004 and in May and June 2005. Rearing conditions varied with species, but most were reared in outdoor concrete or earth ponds. Exceptions were Epinephelus spp., which were reared in indoor concrete tanks, and Chanos chanos and some Eleutheronema tetradactylum, which were reared in outdoor concrete tanks under shade cloth. The aquaculturists we dealt with did not maintain breeding stock, but obtained eggs for rearing from elsewhere. The larvae we obtained from the aquaculturists were placed in oxygenated plastic bags and transported about $1 \mathrm{~h}$ by road to the laboratory at NMMBA. In the laboratory the larvae were acclimated in 401 aquaria filled from the NMMBA seawater system. Each aquarium was fitted with an aerator and kept at ca. $25^{\circ} \mathrm{C}$. Twice daily, 
the larvae were fed with live, newly hatched brine shrimp Artemia nauplii and $50 \%$ of the total volume of water was exchanged with fresh seawater. The aquaria were cleaned daily by suctioning debris off the bottom.

Growth rates were estimated for the larvae in the culture ponds and also during the time larvae were held at NMMBA. In some cases, reliable age estimates for larvae were not available, and in others, age estimates were imprecise. Therefore, growth rate estimates for larvae from the culture ponds were less reliable than those from the laboratory. Growth in the culture pond was estimated by assuming that the larvae were $2 \mathrm{~mm}$ long at hatching and had linear growth, and using the size of larvae on the day we obtained them and the age provided by the aquaculturist. Growth during the time the larvae were held at NMMBA was estimated from the slope of the age versus size regression over that time. Growth estimates were obtained for 6 of the 9 species from the culture ponds; those excluded were Trachinotus blochii, Platax teira and Epinephelus fuscoguttatus. Growth estimates at NMMBA were obtained for 5 of those 6 species; Chanos chanos was excluded.

Reported sizes of larvae are SL in mm. Ages are reported as days after hatch (dah) based on the age reported by the aquaculturist when the larvae were obtained. The nomenclature of early life history stages of fishes is complex, with many different systems of terminology and no consensus on the most appropriate. Depending on the nomenclature used, the individuals we studied (Fig. 1) would be considered larvae or juveniles, or a mixture of both. We do not attempt to distinguish between larvae and juveniles. To avoid awkward phrasing and for simplicity we refer to the young fish under study here as larvae, but acknowledge that some terminologies might refer to them by other labels. In the species studied, notochord flexion was complete at about 4 to $6 \mathrm{~mm}$, depending on species. Therefore, in Chanos chanos, Eleutheronema tetradactylum and Epinephelus fuscoguttatus, all individuals studied were postflexion. In Leiognathus equulus, Lutjanus malabaricus, Platax teira and Trachinotus blochii, the smallest individuals were flexion stage larvae. In Epinephelus coioides and E. malabaricus, the smallest larvae were preflexion stage. The size of the smallest specimens tested was dictated either by the smallest available from the aquaculturists during May and June in Taiwan, or the smallest that we could work with in the swimming chamber. The largest specimens of most species were approximately settlement size. Exceptions were $P$. teira and $T$. blochii for which the largest available larvae were 11 and $6 \mathrm{~mm}$, respectively. In the latter, settlement does not take place as the adults are pelagic.
Multilane swimming chambers were used to measure swimming abilities (Stobutzki \& Bellwood 1994). The chambers were made of clear Perspex with 6 laneways, each $30 \mathrm{~mm}$ wide, $50 \mathrm{~mm}$ high and $180 \mathrm{~mm}$ long. A black line across the lid of the chamber provided the larvae with a point of reference while swimming. Aside from the fine mesh $(0.5 \mathrm{~mm})$ ends, the chamber design was identical to that of Stobutzki \& Bellwood $(1994,1997)$ and they were the same chambers used by Clark et al. (2005) and Leis et al. (2006a,b).

The chambers were plumbed into the seawater system at NMMBA, which provided a continual flow of 'fresh' seawater. Even distribution of flow was achieved by a T-piece diffuser placed in the header portion of the chamber. Turbulence in the chamber was minimised by a $40 \mathrm{~mm}$ long section of flow straighteners at the start of each laneway. This also minimised possible boundary layers. Previous measurements have shown that water velocity in the $5 \mathrm{~mm}$ closest to the wall was not significantly different to that in the centre of the chamber (Stobutzki \& Bellwood 1997, Stobutzki 1998, Fisher et al. 2000). Water flow speed was controlled by turning a calibrated valve. Flow rates were calibrated by recording the time taken for water flowing over the chamber's outlet weir to fill a container of known volume, divided by the cross-sectional area of the chamber. The average of 5 calibrations was used as the flow speed for a given valve angle. The chambers were calibrated several times over the course of the study. Flow speeds in excess of $50 \mathrm{~cm} \mathrm{~s}^{-1}$ could be achieved with this system, but due to vagaries of the seawater system and differences in how the swim chambers were plumbed in the $2 \mathrm{yr}$, the maximum flow was less on some occasions, and some larvae were able to swim faster than the chamber maximum on some occasions (see later discussion of how data from such 'outswimmers' were treated).

Larvae were acclimated to any differences in water quality between holding tank and swim chamber by gradual addition of seawater from the swimming chamber system. Larvae were placed in a chamber lane and allowed to acclimate for $5 \mathrm{~min}$ at $1 \mathrm{~cm} \mathrm{~s}^{-1}$. Any larva showing signs of stress during the acclimation period was removed and replaced with another individual. Water temperature in the swimming chamber ranged from 27 to $31^{\circ} \mathrm{C}$, the ambient temperature in the ocean off southern Taiwan at that time of year.

We measured $U_{\text {crit, }}$ which quantifies maximum swimming speed over periods of minutes. Starting at $1.5 \mathrm{~cm} \mathrm{~s}^{-1}$ flow, speed was increased at a target increment of 2 to $3 \mathrm{~cm} \mathrm{~s}^{-1}$ every $5 \mathrm{~min}$ until the larvae were unable to swim against the flow. Due to vagaries in the seawater system and differences in the plumbing leading to the swim chambers used during 2004 and 2005, 
the actual range in speed increment steps was 1.6 to $3.7 \mathrm{~cm} \mathrm{~s}^{-1}$ when all 6 laneways of the swimming chamber were in use. To achieve a flow speed fast enough to reach $U_{\text {crit }}$ for the larger stages of 3 species, 3 laneways of the swim chamber were closed and the system recalibrated. In this case, the speed increment steps were 5.3 to $5.4 \mathrm{~cm} \mathrm{~s}^{-1}$. The time elapsed at the point when each larva drifted into the downstream mesh ( $t$ in the equation below) was recorded. Critical speed ( $\left.U_{\text {crit }}\right)$ of larvae was calculated following Brett (1964):

$$
U_{\text {crit }}=U+\left(t / t_{\mathrm{i}} \times U_{\mathrm{i}}\right)
$$

where $U=$ penultimate speed, $U_{\mathrm{i}}=$ speed increment (normally ca. $2 \mathrm{~cm} \mathrm{~s}^{-1}$ ), $t=$ time swum in the final speed increment, and $t_{\mathrm{i}}=$ the time interval for each velocity increment (5 min). The total time for a critical speed measurement was proportional to the $U_{\text {crit }}$ achieved and varied from 0.5 min for the smallest slowest individuals (i.e. unable to achieve $1.5 \mathrm{~cm} \mathrm{~s}^{-1}$ ) to $75 \mathrm{~min}$ for the larger fastest individuals. Given the swimming endurance these larvae are capable of (hours to days; J. M. Leis unpubl. data) and that for other warmwater species (Fisher et al. 2000, Clark et al. 2005, Leis et al. 2006a), it is unlikely that the larvae would have become fatigued over such time intervals. Comparisons have shown that varying the time increment $\left(t_{\mathrm{i}}\right)$ and speed increment $\left(U_{\mathrm{i}}\right)$, which results in variations in the time over which the full $U_{\text {crit }}$ test takes place, has little effect on the resultant $U_{\text {crit }}$ value (Fisher et al. 2005).

Fatigued larvae were removed from the chamber, euthanized and fixed in Bouin's solution for $1 \mathrm{~h}$, then transferred into $70 \%$ alcohol and stored. All preserved larvae were later examined under a dissecting microscope to determine SL and stage of development. These specimens are archived in the Fish Collection of the Australian Museum, Sydney (under registration stations AMS I.43864 and I.43865).

A total of 13 individual larvae of 2 species (Lutjanus malabaricus and Epinephelus malabaricus) could maintain position at the highest speed that the chamber could produce in some situations. The true $U_{\text {crit }}$ of these outswimmers was underestimated by an unknown amount. For this reason, their data were not included in the regression analysis but were noted (see Fig. 2).

To determine the best predictor of performance, values of critical swimming speed and endurance were regressed against SL using linear, power and exponential models. The linear model provided the best fit for 5 species. In the other 4 species, the $\mathrm{R}^{2}$ of the linear model was within 0.03 to 0.07 of the $R^{2}$ of the best fit (power) model, and the 2 regression lines were very similar (i.e. the power curve was nearly linear). Therefore, we report here only the linear relationships, although the power and exponential relationships are provided in Appendix 1. Age versus $U_{\text {crit }}$ relationships were also calculated, but these provided a much poorer fit than did the size versus $U_{\text {crit }}$ relationships. Because age and SL are related, we performed another analysis whereby we regressed SL against age for individuals for which we had both variables. The residuals from this analysis (the variation in size that was not due to age, i.e. variation in growth) and SL were used as independent variables in a multiple linear regression against $U_{\text {crit }}$. This analysis could be done for 7 species and allowed an assessment of the relative importance of size and growth rate on swimming performance. In each case, only SL had a significant influence on $U_{\text {crit }}$. The results of these analyses are not included, but they further confirm the superiority of size as a predictor of swimming performance.

In addition to average performance, we also report the speed of the best performers at different sizes. This was done because the best performers may not only have the most influence on dispersal outcomes, but they may be the individuals most likely to survive the extremely high mortality of the larval stage (GrorundColvert \& Sponaugle 2006).

To study larvae from a wide variety of sizes and stages of development, we either obtained multiple cohorts from aquaculturists or kept larvae in the NMMBA laboratory while they grew. Thus, for all species the $U_{\text {crit }}$ data were collected from more than one day (although the same larvae were never measured more than once), and for most species from more than one cohort of larvae (Table 1). We attempted to ensure that the size ranges of larvae tested on different days overlapped as much as possible, but overlap was not always achieved. Although there were never enough measurements from different cohorts or days to formally test to see if inclusion of data from different cohorts or days introduced additional variance, there was some evidence that it did so (e.g. omission of measurements from one day might result in an increase in overall $\mathrm{R}^{2}$ ). However, as there was no basis for determining which cohorts or days provided the most representative data, they are all included in our analysis.

\section{RESULTS}

We obtained rough growth estimates of 2 types. Growth rates for larvae in the culture ponds were 0.08 to $0.72 \mathrm{~mm} \mathrm{~d}^{-1}$ for 6 species with a mean of $0.30 \mathrm{~mm}$ $\mathrm{d}^{-1}$. Growth for larvae at NMMBA was 0.30 to $0.62 \mathrm{~mm}$ $\mathrm{d}^{-1}$ for 5 species with a mean of $0.40 \mathrm{~mm} \mathrm{~d}^{-1}$.

The $U_{\text {crit }}$ values ranged from 0 to $64 \mathrm{~cm} \mathrm{~s}^{-1}$. As expected, $U_{\text {crit }}$ increased with increasing size of the larvae in each species (Table 2, Fig. 2), although in most 
Table 2. Relationships between critical speed $\left(U_{\text {crit }}\right.$ in $\left.\mathrm{cm} \mathrm{s}^{-1}\right)$ and size, $U_{\text {crit }}\left(\mathrm{cm} \mathrm{s}^{-1}\right)$ and age (days after hatch [dah]) and $U_{\text {crit }}($ body lengths $\left.[\mathrm{BL}] \mathrm{s}^{-1}\right)$ and size. $\mathrm{CI}=$ confidence interval, $\mathrm{ns}=$ not significant $(\mathrm{p}>0.05), \mathrm{nd}=$ no data available

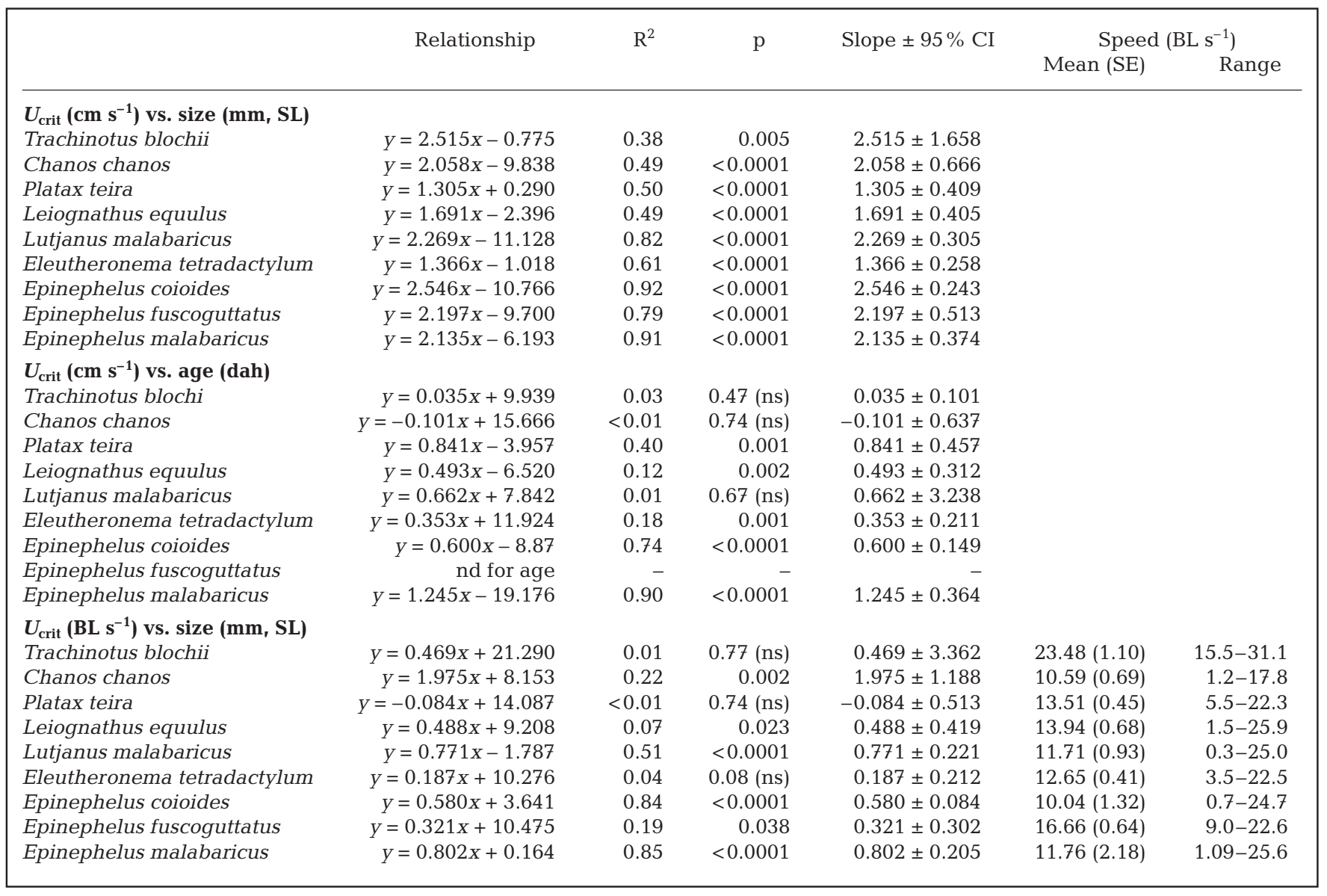

cases the variation in speed at any size was large. The speed versus size relationships were linear or approximately so; the slopes were significantly different from zero and, with one exception (Trachinotus blochii, in which only larvae of 4 to $6 \mathrm{~mm}$ were available), explained at least $49 \%$ of the variation in speed. The rate of increase in speed ranged from 1.31 to $2.64 \mathrm{~cm}$ $\mathrm{s}^{-1}$ for each $1 \mathrm{~mm}$ increase in size. The increase in speed from the smallest larvae studied to settlement stage larvae ranged from 6- to 100-fold, depending on species.

In general, size was a much better predictor of $U_{\text {crit }}$ than was age (Table 2). No age estimate was available for the Epinephelus fuscoguttatus larvae, and for most species, an age estimate was not available for all individuals tested. Of the 8 species for which some age data were available, 5 had a significant relationship between age and $U_{\text {crit, }}$ but in 7 of the 8 species, the relationship explained considerably less of the variation in $U_{\text {crit }}$ than did size (10 to $82 \%$ less overall and 10 to $43 \%$ in species with a significant age: $U_{\text {crit }}$ relationship; Table 2). In the exceptional species, E. malabari- cus, $90 \%$ of the variation was explained by both relationships. Growth rates in aquaculture environments are unlikely to be representative of those in the wild, so these speed versus age relationships should be used with caution.

To determine whether the slopes of the regressions of $U_{\text {crit }}$ on size differed among species, an analysis of covariance (ANCOVA) was performed with $U_{\text {crit }}$ as the dependent variable, species as a fixed factor and size as the co-variate. ANCOVA revealed a significant interaction between species and size (factor $\times$ co-variate; $\left.F_{(8,372)}=6.440, \mathrm{p}<0.0001\right)$ indicating that the slopes of the various regressions of $U_{\text {crit }}$ on size were not homogenous; i.e. the influence of size on $U_{\text {crit }}$ differed among species. Examination of the regression slopes and their 95\% confidence limits (Table 2) suggested that the species could be loosely placed into 2 groups: those with slopes less than 2 (Platax teira, Leiognathus equulus, and Eleutheronema tetradactylum) and those with slopes greater than 2 (Trachinotus blochii, Chanos chanos, Lutjanus malabaricus, Epinephelus coioides, E. fuscoguttatus and E. malabari- 

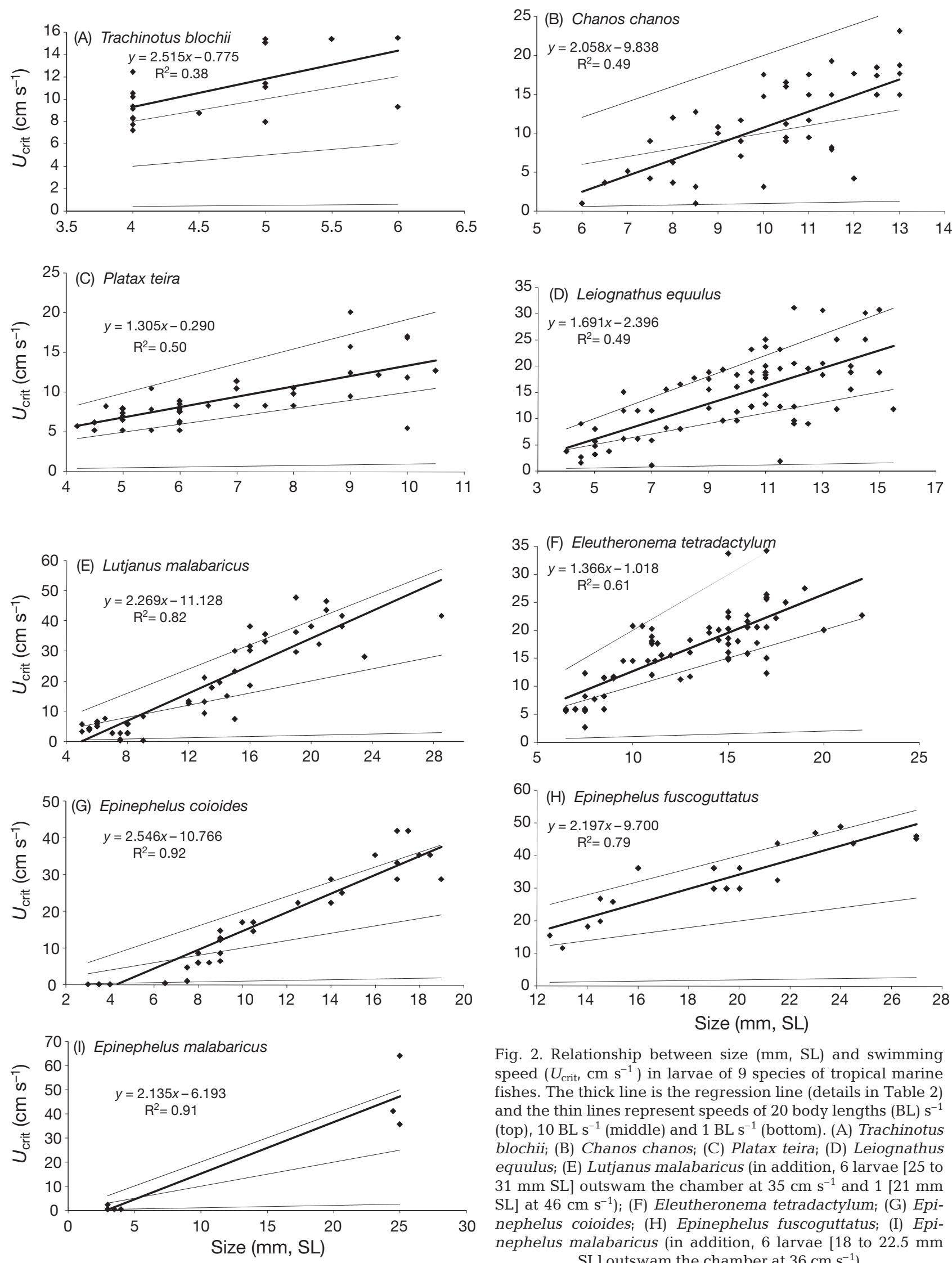

Fig. 2. Relationship between size ( $\mathrm{mm}, \mathrm{SL})$ and swimming speed $\left(U_{\text {crit }}, \mathrm{cm} \mathrm{s}^{-1}\right)$ in larvae of 9 species of tropical marine fishes. The thick line is the regression line (details in Table 2) and the thin lines represent speeds of 20 body lengths (BL) s ${ }^{-1}$ (top), $10 \mathrm{BL} \mathrm{s}^{-1}$ (middle) and $1 \mathrm{BL} \mathrm{s}^{-1}$ (bottom). (A) Trachinotus blochii; (B) Chanos chanos; (C) Platax teira; (D) Leiognathus equulus; (E) Lutjanus malabaricus (in addition, 6 larvae [25 to $31 \mathrm{~mm} \mathrm{SL}$ ] outswam the chamber at $35 \mathrm{~cm} \mathrm{~s}^{-1}$ and 1 [21 $\mathrm{mm}$ $\mathrm{SL}$ ] at $\left.46 \mathrm{~cm} \mathrm{~s}^{-1}\right)_{i}(\mathrm{~F})$ Eleutheronema tetradactylum; (G) Epinephelus coioides; (H) Epinephelus fuscoguttatus; (I) Epinephelus malabaricus (in addition, 6 larvae [18 to $22.5 \mathrm{~mm}$ $\mathrm{SL}$ ] outswam the chamber at $36 \mathrm{~cm} \mathrm{~s}^{-1}$ ) 
cus). When these groups were analysed separately, neither group had a significant interaction between species and size (for slope $>2: F_{(5,182)}=0.86, \mathrm{p}=0.51$; for slope $\left.<2: F_{(2,190)}=1.27, \mathrm{p}=0.28\right)$ indicating that regression slopes did not differ among species within the groups. An ANCOVA on these 2 groups with slope $(>2$ or $<2)$ as the factor confirmed that regression slopes differed significantly between the 2 groups $\left(F_{(1,372)}=30.96, \mathrm{p}<0.001\right)$.

Mean speeds expressed in terms of body lengths (BL) (length-specific $U_{\text {crit }}$ ) ranged from 9.8 to $23.5 \mathrm{BL}$ $\mathrm{s}^{-1}$ (Table 2) depending on species. In all species, except Chanos chanos, at least 1 individual had a maximum length-specific $U_{\text {crit }}$ greater than $20 \mathrm{BL} \mathrm{s}^{-1}$ (range of maximum length-specific $U_{\text {crit }}$ among species was 17.8 to $31.1 \mathrm{BL} \mathrm{s}^{-1}$ ). Six of the 9 species had significant linear relationships between length-specific speed and SL $\left(p<0.05, R^{2}=0.07-0.90\right.$ depending on species; Table 2), confirming an increase in lengthspecific $U_{\text {crit }}$ with increase in size. In every species, the amount of variation in length-specific $U_{\text {crit }}$ explained by the linear relationships was less than for $U_{\text {crit }}$ although the difference ranged from 4 to $60 \%$.

For each species, within each $1 \mathrm{~mm}$ increment of size for which $U_{\text {crit }}$ values for at least 2 individuals were obtained, the speed of the fastest individual was compared with the mean speed to quantify the difference between best performers and average performers. Depending on species, the best performers averaged 1.5 to $7.3 \mathrm{~cm} \mathrm{~s}^{-1}$ faster than did mean performers (Table 3), but with some individuals swimming as much as $15 \mathrm{~cm} \mathrm{~s}^{-1}$ faster than the species mean. A significant relationship between size and the difference between best and mean performance was evident only in Leiognathus equulus larvae, where the difference between best and mean speed increased at a rate of $0.65 \mathrm{~cm} \mathrm{~s}^{-1}$ per $\mathrm{mm}$ increase in size (speed difference $=$ $0.65[\mathrm{SL}]+0.77, \mathrm{p}=0.014, \mathrm{R}^{2}=0.468$ ). It is likely that

Table 3. Comparison of best (fastest) vs. average swimmers $\left(U_{\text {crit }}\right) . N$ is the number of $1 \mathrm{~mm}$ size increments for which more than 1 individual was measured. The mean and greatest differences in $U_{\text {crit }}$ are across all $1 \mathrm{~mm}$ size increments. Epinephelus malabaricus is omitted due to insufficient number of size increments with more than 1 individual

\begin{tabular}{|lccc|}
\hline Species & $\begin{array}{c}N \text { (size } \\
\text { increments) }\end{array}$ & $\begin{array}{c}\text { Mean diff. } \\
\left(\mathrm{cm} \mathrm{s}^{-1}\right)(\mathrm{SE})\end{array}$ & $\begin{array}{c}\text { Greatest diff. } \\
\left(\mathrm{cm} \mathrm{s}^{-1}\right)\end{array}$ \\
\hline Trachinotus blochii & 3 & $2.87(0.29)$ & 3.2 \\
Chanos chanos & 8 & $4.38(0.84)$ & 7.6 \\
Platax teira & 7 & $2.68(0.74)$ & 6.1 \\
Leiognathus equulus & 12 & $7.28(0.99)$ & 15.3 \\
Lutjanus malabaricus & 15 & $3.60(0.84)$ & 9.8 \\
Eleutheronema tetradactylum & 12 & $3.26(0.85)$ & 11.5 \\
Epinephelus coioides & 7 & $1.91(0.65)$ & 5.5 \\
Epinephelus fuscoguttatus & 6 & $3.71(0.78)$ & 5.6 \\
\hline
\end{tabular}

within a species, the magnitude of the difference recorded between mean and best performance is positively correlated with the number of individuals measured. Thus, the 'best performance' we report is likely to be an underestimate of the true best performance within the population of larvae.

\section{DISCUSSION}

The chief advantage of using $U_{\text {crit }}$ to investigate the ontogeny of swimming performance in fish larvae is the ability to compare swimming speed among developmental stages and among species. In the larvae of the 9 species we examined, $U_{\text {crit }}$ increased rapidly with increase in size and the rate of increase varied among species. Further, the absolute magnitude of the increase from the smallest larvae to settlement size varied greatly among species. Variation in $U_{\text {crit }}$ at any size was high, as has been found also in previous studies of both reared and wild larvae (Fisher et al. 2000, 2005, Clark et al. 2005, Leis et al. 2006a).

Morphology undoubtedly influences swimming speed (Fisher et al. 2005). The larvae tested here had 4 basic morphologies (Fig. 1): (1) clupeid-like, i.e. very elongate with a long, straight gut along the ventral edge (Chanos chanos); (2) generalized perciform, i.e. moderate depth, laterally compressed, with a compact gut (Trachinotus blochii, Leiognathus equulus, Eleutheronema tetradactylum); (3) generalized perciform morphology, but with very elongate spines in dorsal and pelvic fins (Epinephelus spp., Lutjanus malabaricus); and (4) rotund, i.e. head and trunk deep and broad with a small, compressed tail (Platax teira).

The smallest (6 to $7 \mathrm{~mm}$, SL) Chanos chanos larvae (clupeid-like morphology) were slower than similarsized generalized perciform larvae. However, C. chanos larvae increased in speed rapidly with increase in size, so that by $13 \mathrm{~mm}$ (settlement size) their $U_{\text {crit }}$ was similar to those of both the generalized perciforms and the perciforms with elongate fin spines.

The rotund species (Platax teira) and 2 of the generalized perciform species (Leiognathus equulus, Eleutheronema tetradactylum) had similar initial performance and rate of increase in $U_{\text {crit }}$. Over the narrow range of sizes for which we had data, Trachinotus blochii, the third generalized perciform species, had the best swimming performance, with the fastest $U_{\text {crit }}$ values at $4 \mathrm{~mm} \mathrm{SL}$ and a rate of increase in $U_{\text {crit }}$ with increase in size that was among the highest we measured in this 
study. The swimming performance of $T$. blochii is similar to that of another carangid, Caranx ignobilis (Fig. 3).

The 3 Epinephelus species were initially slow swimmers, with very low $U_{\text {crit }}$ values until reaching about 7 to $8 \mathrm{~mm}$ SL, but speed improved rapidly after that and they were among the fastest swimming larvae at settlement size. The initially poor swimming performance of the Epinephelus larvae was probably related to the very long, robust, bony spines of their dorsal and pelvic fins (more than half the length of the body). These large defensive spines are probably an impediment to swimming, and small larvae of these species may have a behaviour in relation to predators and prey that relies on stealth and deception rather than speed or manoeuvrability (Moser 1981). In these 3 Epinephelus species, the fin spines reach a maximum relative length (50 to $70 \%$ of SL) at about 5 to $6 \mathrm{~mm}$, approximately the same size that notochord flexion and concomitant caudal fin formation are underway (Doi et al. 1991, Kohno et al. 1993, Leu et al. 2005). At slightly larger sizes, when the relative size of the fin spines is decreasing and the caudal fin is fully formed, meaningful swimming ability begins to be displayed. From this, it seems likely that the smallest Epinephelus larvae $(<8 \mathrm{~mm})$ will have limited ability to directly influence dispersal outcomes. Given the similarity in the ontogeny of $U_{\text {crit }}$ among these 3 species and the fact that their morphology is similar to that of other epinephelin serranid larvae (Baldwin et al. 2004), this

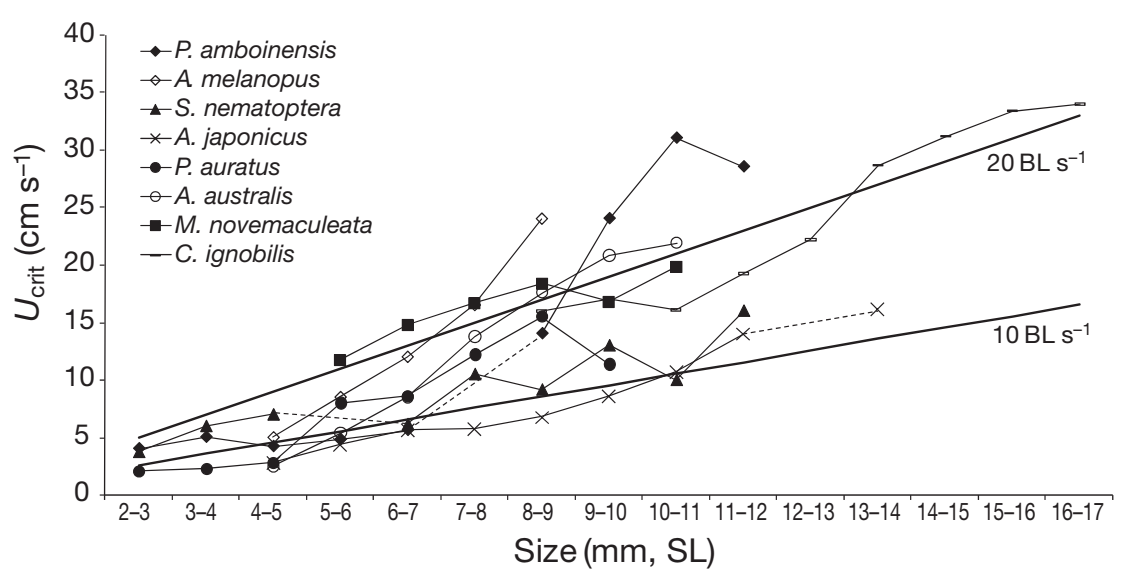

Fig. 3. Ontogeny of $U_{\text {crit }}$ in larvae of tropical and warm-temperate fish species. Plotted values are mean $U_{\text {crit }}$ at $1 \mathrm{~mm}$ increments of length (SL). Data for: Pomacentrus amboinensis (Pomacentridae), Amphiprion melanopus (Pomacentridae) and Sphaeramia nematoptera (Apogonidae) from Fisher et al. (2000); Argyrosomus japonicus (Sciaenidae), Pagrus auratus (Sparidae), Acanthopagrus australis (Sparidae) and Macquaria novemaculeata (Percichthyidae) from Clark et al. (2005); Caranx ignobilis (Carangidae) from Leis et al. (2006a). Species represented by symbols of the same shape are in the same family. The pomacentrids and apogonid hatch from non-pelagic eggs, whereas the sciaenid, sparids and the percicithyid hatch from pelagic eggs. The size versus speed relationships of the 9 study species from the present paper are provided in this same format in Appendix 2 conclusion can be expected to apply to larvae of other epinephelin serranid species (i.e. sea basses and roupers). Pooling data for the 3 Epinephelus species in a strong relationship $\left(U_{\text {crit }}=2.815[\mathrm{SL}]-7.960\right.$, nephelin species.

Larvae of the lutjanid Lutjanus malabaricus also have elongate spines in dorsal and pelvic fins (20 to $35 \%$ of SL), although not as long as in the Epinephelus spp. However, the smallest L. malabaricus larvae we tested were $2 \mathrm{~mm}$ larger than the smallest Epinephelus arvae. Although it is not clear if both have limited wimming abilities when very small, at the smallest ze they have in common in this study ( $5 \mathrm{~mm}$ SL), the $U_{\text {crit }}$ values of the 2 genera were similar (Fig. 2). Larvae the genera Lutjanus and Epinephelus had similar (nit $U_{\text {crit }}$ with over the common size range. development (the smallest sizes tested in all but the 3 Epinephelus species, and from about 7 to $8 \mathrm{~mm}$ in those species), the larvae of the species we studied were able to swim at speeds that placed them outside f the strictly viscous hydrodynamic environment (i.e. Reynolds number $>300$ ) and fast enough to influence dispersal outcomes (Leis 2006). At tropical temperaand this includes most of the species considered here. The speeds of the larvae we studied were overwhelmingly in the range of 10 to $20 \mathrm{BL} \mathrm{s}^{-1}$ and all species were capable of $10 \mathrm{~cm} \mathrm{~s}^{-1}$ before settlement. A current speed of $10 \mathrm{~cm} \mathrm{~s}^{-1}$ is typical in many coastal environments (Fisher 2005), which means that the larvae of these species are capable of swimming faster than average current speeds (i.e. are 'effective swimmers'; sensu Leis \& Stobutzki 1999) well before settlement in many locations. Heuristic modelling indicates that speeds as low as 1 to $5 \mathrm{~cm} \mathrm{~s}^{-1}$ can influence dispersal outcomes (Leis 2006). Based on extrapolation of the speed versus size relationships from our $U_{\text {crit }}$ measurements, average speeds of $1 \mathrm{~cm} \mathrm{~s}^{-1}$ can be attained by the species studied at 1.8 to $6.7 \mathrm{~mm} \mathrm{SL}$, and larvae 1.5 to 2.5 $\mathrm{mm}$ larger can attain speeds of $5 \mathrm{~cm} \mathrm{~s}^{-1}$. Extrapolation of these relationships to larvae smaller than 5 to $6 \mathrm{~mm}$ is somewhat dubious as in most of these species such small larvae would not have completed notochord flexion, and different speed versus size relationships may apply before the caudal fin is formed. It is 
clear, however, that small larvae can achieve speeds that are meaningful in the context of dispersal.

The fastest larvae were able to swim considerably faster than mean performance at any size. This means these exceptional larvae (i.e. best performers) achieve a given swimming speed at smaller sizes, and at any size will have a greater potential to influence dispersal outcomes. Therefore, this variance in size should be taken into account when developing biophysical models of larval fish dispersal. Such models would be an ideal means of examining the dispersal implications of exceptional swimming performance. Further, several lines of evidence indicate that it may be the exceptional rather than average individuals that survive the very high mortality rates during the pelagic larval period (Leis 2007). Although growth has been most often studied in this respect, exceptional swimming ability may also lead to increased survival, and it is possible that exceptional rather than average performance is the appropriate metric for biophysical dispersal models.

Although $U_{\text {crit }}$ is sometimes referred to as a measure of sustainable speed (e.g. Stobutzki \& Bellwood 1994), $U_{\text {crit }}$ is, in fact, measured over only short periods (i.e. minutes) and is technically a measure of prolonged swimming speed (as distinct from both burst speed and sustainable speed; Plaut 2001). The $U_{\text {crit }}$ is best thought of as a measure of potential performance. It is unlikely that larvae in the sea actually swim at their $U_{\text {crit }}$ speed for sustained periods, so $U_{\text {crit }}$ is not a realistic measure of performance in the sea (Leis 2006). However, there are indications that $U_{\text {crit }}$ can be used to predict larval swimming performance in the sea. Fisher \& Wilson (2004) concluded that a speed of about one-half of $U_{\text {crit }}$ was sustainable over periods of $24 \mathrm{~h}$, and empirical evidence shows that larvae in the sea actually swim (i.e. in situ speed; Leis \& Carson-Ewart 1997) at about 30 to $50 \%$ of $U_{\text {crit }}$ (Leis \& Fisher 2006, Leis et al. 2006a,b, 2007). This is important because measurement of $U_{\text {crit }}$ in the laboratory is much easier and more efficient than measuring in situ swimming in the sea. Further, it is possible to work with much smaller larvae in the laboratory than in the sea; therefore, to the extent that the relationships between $U_{\text {crit }}$ and in situ speed can be extrapolated to smaller larvae, laboratory testing allows the possibility of obtaining realistic estimates of swimming speed in the sea for much smaller larvae.

Because swimming performance of reared larvae may not be representative of performance of wild larvae, it is important to compare performance of wild and reared larvae where possible (Leis 2006). Unfortunately, our ability to make such comparisons was constrained by limited data on swimming performance in wild larvae. The only comparisons that could be made between our reared larvae and wild larvae of the same or closely related species are for settlement stage larvae of the lutjanids and serranids; no $U_{\text {crit }}$ data are available for wild larvae of the other families or for other developmental stages. Wild settlement stage larvae of 4 species of Lutjanus (L. analis, L. carponotatus, L. cyanopterus and L. quinquelineatus) with settlement sizes similar to those of L. malabaricus (21 to $26 \mathrm{~mm} \mathrm{SL}$ ) had mean $U_{\text {crit }}$ values of 40 to $52 \mathrm{~cm} \mathrm{~s}^{-1}$ ( $\mathrm{SE}=0.9$ to 5.4) (Fisher et al. 2005). Over the size range of 21 to $26 \mathrm{~mm} \mathrm{SL}$, reared L. malabaricus larvae had average $U_{\text {crit }}$ values predicted by the regression equation (Table 2) of 38 to $51 \mathrm{~cm} \mathrm{~s}^{-1}$ (and measured SE $=1.4$ to 2.9); this performance is equivalent to the wild larvae of the other 4 Lutjanus species. Epinephelus and Plectropomus are closely related genera of the same serranid tribe and their settlement stage larvae are morphologically similar (Leis 1986). Settlement stage $P$. leopardus larvae (17 $\mathrm{mm} \mathrm{SL}$ ) had an average $U_{\text {crit }}$ of $31.5 \mathrm{~cm} \mathrm{~s}^{-1}(\mathrm{SE}=3.2)$ (Fisher et al. 2005), whereas $17 \mathrm{~mm}$ SL larvae of the 3 Epinephelus spp. had average $U_{\text {crit }}$ values of 27 to $33 \mathrm{~cm} \mathrm{~s}^{-1}$ ( $\mathrm{SE}=1.3$ to 3.3). Thus, $U_{\text {crit }}$ values in the 2 serranid genera are equivalent. Therefore, to the extent that we could compare $U_{\text {crit }}$ performance of wild and reared larvae, the values were essentially identical in terms of both mean and variation.

There was no indication that growth rates of the reared larvae were substantially different from those of wild larvae. This is an issue because it is desirable that reared larvae are as similar as possible to wild larvae to help ensure that their behaviours are equivalent. With the exception of Chanos chanos, essentially nothing is known about growth rates of wild larvae of any of the species we studied. Growth estimates for wild and reared C. chanos larvae appear similar; wild larvae of C. chanos between 5 and $14 \mathrm{~mm}$ SL were estimated to grow at $0.5 \mathrm{~mm} \mathrm{~d}^{-1}$ (Bagarinao 1991), and in the Taiwanese aquaculture farms, larvae of $C$. chanos grew at $0.37 \mathrm{~mm} \mathrm{~d}^{-1}$. Growth rates of reared larvae of the other species in our study (0.08 to $0.72 \mathrm{~mm} \mathrm{~d}^{-1}$ ) were within the range of mean values reported for wild marine fish larvae (Benoit et al. 2000, Meekan et al. 2003), indicating that they do not differ from wild larvae in this respect.

Obtaining larvae from the aquaculture industry has several advantages, most notably that we neither had to maintain the extensive infrastructure necessary for rearing marine fish larvae nor develop the species-specific methods required to obtain optimal survival and growth in captivity. Working in Taiwan, where a wide variety of species is under culture, was also advantageous (Yu 2002). Disadvantages include the sometimes vague information we received on larval ages and the lack of control over availability of species or develop- 
mental stages. For example, Taiwanese aquaculturists were reluctant to provide Epinephelus larvae in the middle stages of development (ca. 6 to $10 \mathrm{~mm}$ ), stating that larvae were particularly fragile at these stages and that the disturbance required to capture larvae for us would be detrimental to larvae remaining in the culture pond. This influenced the size range available to us of some of the study species.

Although the patterns of ontogeny of swimming varied among species studied here, the variation was within relatively narrow bounds. The 9 species considered here generally swam at between 10 and $20 \mathrm{BL} \mathrm{s}^{-1}$ throughout their larval development and regardless of size. This is in agreement with results on other tropical and warm-temperate marine fish species (Fig. 3). The 8 other species for which data on ontogeny of $U_{\text {crit }}$ exist also swam in most cases at between 10 and $20 \mathrm{BL} \mathrm{s}^{-1}$ throughout their larval development. At one extreme, larger larvae of the 2 pomacentrid species swam somewhat faster than this, reaching speeds of about $30 \mathrm{BL}$ $\mathrm{s}^{-1}$ (Fig. 3), whereas at the other extreme, larvae of a sciaenid swam at just under $10 \mathrm{BL} \mathrm{s} \mathrm{s}^{-1}$ at all but the largest sizes (Fisher et al. 2000, Clark et al. 2005). Similar to the species we studied, these other species had an approximately linear increase in swimming speed with the increase in size, with one apparent exception: a pomacentrid Pomacentrus amboinensis seemed to have an allometric 2-phased increase in swimming ability, with little increase in speed until larvae reached about $8 \mathrm{~mm}$ SL, after which speed increased markedly (Fisher et al. 2000).

In contrast, the within-species increase in $U_{\text {crit }}$ between the smallest larvae and those at settlement stage differed markedly among species, principally due to among-species differences in the rate of increase of $U_{\text {crit }}$ with increase in size and differences in size at settlement. In the species for which the smallest studied larvae were 4 to $5 \mathrm{~mm} \mathrm{SL}$, the increase in speed by settlement stage was 6-fold for Leiognathus equulus and 100-fold for Epinephelus coioides. For species in which the smallest larvae were 5 to $6 \mathrm{~mm} \mathrm{SL}$, the increase in speed was 5- to 6-fold for Chanos chanos and Eleutheronema tetradactulm, but 10-fold for Lutjanus malabaricus. This is a further indication of the substantial differences among species in the ontogeny of swimming abilities.

Although the majority of tropical, demersal teleost fish families spawn pelagic eggs (Leis 1991), many families that do not spawn pelagic eggs (e.g. Apogonidae, Blenniidae, Gobiidae, Pomacentridae) are very speciose (Nelson 2006). Therefore, both spawning modes are well represented. In both spawning groups, morphological developmental events relevant to swimming, such as notochord flexion and concomitant formation of the caudal fin, tend to occur at about the same size (Leis \& Carson-Ewart 2004); the main developmental difference between groups is simply size at hatching. Larvae hatching from non-pelagic eggs tend to be larger, and therefore, more developed than those from pelagic eggs (Thresher 1984, Moser 1996, Leis \& Carson-Ewart 2004), and as a result, they may be better swimmers initially. There were, however, no consistent differences in the ontogeny of swimming ability between these 2 groups (Fig. 3). Three of the species represented in Fig. 3 hatch from non-pelagic eggs: the 2 pomacentrids, Pomacentrus amboinensis and Amphiprion melanopus, and the apogonid, Sphaeramia nematoptera. Two of these species had linear increases in speed with increase in size, whereas the third did not (Fisher et al. 2000); the apogonid was among the slowest species studied and had the slowest rate of increase in speed, whereas the later stages of the 2 pomacentrids were among the fastest larvae on a per size basis and had high rates of increase in swimming speed. Due to the differences in size and development at hatching, it might be expected that any difference in swimming ability between the 2 spawning groups would be most obvious at smaller sizes, but this was not the case (Fig. 3). Small and mid-size larvae from non-pelagic eggs swam at speeds similar to similarsize larvae from pelagic eggs. Despite this lack of sizerelated difference in swimming performance between the 2 groups, there may be age-related (i.e. days after hatch) differences in swimming performance between the 2 groups. This question is difficult to address with reared larvae because growth rates and variations thereof are unlikely to be the same as those in wild larvae.

The available data indicate that a one-size-fits-all model of fish swimming ontogeny is not a realistic expectation. Although a linear model of increase in speed over the size range studied was appropriate for our 9 test species, the previously studied species with the highest relative speed (a pomacentrid, Fig. 3) had a different size:speed relationship. Even for the species with linear relationships between swimming speed and size, the 2 critical factors in the relationships differed; both the rate of increase of speed with increase in size and the actual speeds attained differed among species (as did length-specific speed). Closely related species did, however, have similar speed:size relationships. Finally, there are reasons to expect that larvae of cool-water and cold-water species will not have swimming abilities or size:speed relationships similar to those of tropical species (Leis 2007), but so few $U_{\text {crit }}$ data are available for cooler-water taxa that this expectation cannot be tested at present.

In conclusion, we provide for the first time information on the ontogeny of swimming performance in the larvae of medium to large species (and families) of 
tropical marine fishes that hatch from pelagic eggs; most are of major commercial importance. Early in their development, larvae of these species are able to swim strongly and attain speeds that place them outside of the inefficient viscous hydrodynamic environment. Such speeds are able to influence their dispersal outcomes. Speeds of 10 to $20 \mathrm{BL} \mathrm{s}^{-1}$ were typical, and some were as high as $64 \mathrm{~cm} \mathrm{~s}^{-1}$. Size was a better predictor of swimming performance than was age. Swimming speeds increased at species-specific linear rates of 1.3 to $2.6 \mathrm{~cm} \mathrm{~s}^{-1}$ for each $1 \mathrm{~mm}$ increase in size. The fastest individuals were considerably faster than average, and this may be important for biophysical dispersal models. This swimming performance can now be taken into account in numerical, biophysical dispersal models and other applications that require information on the development of swimming ability in fish larvae.

Acknowledgements. We thank Dr. K.-T. Shao, Academica Sinica, who made our work in Taiwan possible. We also thank the staff of NMMBA for their excellent cooperation, particularly Dr. I.-S. Chen and C.-Y. Chung. Our work could not have proceeded without the assistance of C. Wen and K.-P. Kan. L.-H. Chao generously introduced us to many Taiwanese aquaculturists and spent many hours helping us obtain larvae. D. Clark, M. Brown and R. Piola assisted ably. R. Johnson confirmed identification of one species using DNA. G. Howarth and S. Bullock provided editorial assistance. This research was supported by an ARC Discovery Grant (DP0345876) and a DST International Science Linkages Grant (IAP-IST-CG030043) to J.M.L., and by the Australian Museum.

\section{LITERATURE CITED}

Bagarinao TU (1991) Biology of milkfish (Chanos chanos Forsskål). Southeast Asian Fisheries Development Center, Iloilo

Baldwin CC, Leis JM, Rennis DS (2004) Epinephelinae, tribes Niphonini and Epinephelini (groupers, rock-cods, coral trouts). In: Leis JM, Carson-Ewart BM (eds) The larvae of Indo-Pacific coastal fishes: a guide to identification (Fauna Malesiana Handbook 2). Brill, Leiden, p 377-382

Benoit HP, Pepin P, and Brown JA (2000) Patterns of metamorphic age and length in marine fishes, from individuals to taxa. Can J Fish Aquat Sci 57:856-869

Brett JR (1964) The respiratory metabolism and swimming performance of young sockeye salmon. J Fish Res Board Can 21:1183-1226

Clark DL, Leis JM, Hay AC, Trnski T (2005) Swimming ontogeny of larvae of four temperate marine fishes. Mar Ecol Prog Ser 292:287-300

Cowen RK, Paris CB, Sirnivasan A (2006) Scaling of connectivity in marine populations. Science 311:522-527

Doi M, Munir MN, Nik Razali NL, Zulkifli T (1991) Artificial propagation of the grouper, Epinephelus suillus $[=E$. coioides], at the marine finfish hatchery at Tanjong Demong, Terengganu, Malaysia. Kertas Pengembangan Perikanan Bil 167:1-41

Fisher R (2005) Swimming speeds of larval coral reef fishes: impacts on self-recruitment and dispersal. Mar Ecol Prog Ser 285:223-232

Fisher R, Bellwood DR, Job SD (2000) Development of swim- ming abilities in reef fish larvae. Mar Ecol Prog Ser 202:163-173

Fisher R, Leis JM, Clark DL, Wilson SK (2005) Critical swimming speeds of late-stage coral reef fish larvae: variation within species, among species and between locations. Mar Biol 147:1201-1212

Fisher R, Wilson SK (2004) Maximum sustainable swimming speeds of late-stage larvae of nine species of reef fishes. J Exp Mar Biol Ecol 312:171-186

Grorund-Colvert K, Sponaugle S (2006) Influence of condition on behavior and survival potential of newly settled coral reef fish, the bluehead wrasse, Thalassoma bifasciatum. Mar Ecol Prog Ser 327:279-288

Kohno H, Daini S, Supriatna A (1993) Morphological development of larval and juvenile grouper, Epinephelus fuscoguttatus. Jpn J Ichthyol 40:307-316

Leis JM (1986) Larval development of four species of the IndoPacific coral trout genus Plectropomus (Pisces: Serranidae: Epinephelinae) with an analysis of the relationships of the genus. Bull Mar Sci 38:525-552

Leis JM (1991) The pelagic phase of coral reef fishes: larval biology of coral reef fishes. In: Sale PF (ed) The ecology of fishes on coral reefs. Academic Press, San Diego, CA, p 183-230

Leis JM (2006) Are larvae of demersal fishes plankton or nekton? Adv Mar Biol 51:59-141

Leis JM (2007) Behaviour of fish larvae as an essential input for modelling larval dispersal: behaviour, biogeography, hydrodynamics ontogeny, physiology and phylogeny meet hydrography. Mar Ecol Prog Ser 322:225-238

Leis JM, Carson-Ewart BM (1997) Swimming speeds of the late larvae of some coral reef fishes. Mar Ecol Prog Ser 159:165-174

Leis JM, Carson-Ewart BM (2004) The larvae of Indo-Pacific coastal fishes: a guide to identification (Fauna Malesiana Handbook 2). Brill, Leiden

Leis JM, Fisher R (2006) Swimming speed of settlement-stage reef-fish larvae measured in the laboratory and in the field: a comparison of critical speed and in situ speed. Proc 10th Int Coral Reef Symp, Okinawa: 438-445

Leis JM, Stobutzki IC (1999) Swimming performance of late pelagic larvae of coral-reef fishes: in situ and laboratorybased measurements. In: Séret B, Sire JY (eds) Proc 5th Indo-Pacific Fish Conf, Nouméa, 1997. Société Française d'Ichtyologie et Institut de Recherche pour le Développment, Paris, p 575-583

Leis JM, Hay AC, Clark DA, Chen IS, Shao KT (2006a) Behavioral ontogeny in larvae and early juveniles of the giant trevally, Caranx ignobilis (Pisces: Carangidae). Fish Bull 104:401-414

Leis JM, Hay AC, Trnski T (2006b) In situ behavioural ontogeny in larvae of three temperate, marine fishes. Mar Biol 148:655-669

Leis JM, Wright KJ, Johnson RN (2007) Behaviour that influences dispersal and connectivity in the small, young larvae of a reef fish. Mar Biol 153:103-117

Leu MY, Liou CH, Fang LS (2005) Embryonic and larval development of the malabar grouper, Epinephelus malabaricus (Pisces: Serranidae). J Mar Biol Assoc UK 85:1249-1254

Meekan MG, Carleton JH, McKinnon AD, Flynn K, Furnas M (2003) What determines the growth of tropical reef fish larvae in the plankton: food or temperature? Mar Ecol Prog Ser 256:193-204

Moser HG (1981) Morphological and functional aspects of marine fish larvae. In: Lasker R (ed) Marine fish larvae: morphology, ecology and relation to fisheries. University 
of Washington Press, Seattle, p 90-130

Moser HG (1996) The early stages of fishes in the California Current region. Calif Coop Ocean Fish Invest Atlas 33:1-1505

Neira FJ, Miskiewicz AG, Trnski T (1998) Larvae of temperate Australian fishes: laboratory guide for larval fish identification. University of Western Australia Press, Nedlands

Nelson JS (2006) Fishes of the world, 4th edn. J Wiley, Hoboken, NJ

Plaut I (2001) Critical swimming speed: its ecological relevance. Comp Biochem Physiol A Comp Physiol 131:41-50

Stobutzki IC (1998) Interspecific variation in sustained swimming ability of late pelagic stage reef fish from two fami- lies (Pomacentridae and Chaetodontidae). Coral Reefs 17:111-119

Stobutzki IC, Bellwood DR (1994) An analysis of the sustained swimming abilities of pre- and post-settlement coral reef fishes. J Exp Mar Biol Ecol 175:275-286

Stobutzki IC, Bellwood DR (1997) Sustained swimming abilities of the late pelagic stages of coral reef fishes. Mar Ecol Prog Ser 149:35-41

Thresher RE (1984) Reproduction in reef fishes. TFH Publications, Neptune City, NJ

Yu NH (2002) New challenges: breeding species in Taiwan, VIII. Fish Breeding Association of the Republic of China, Kaohsiung, Taiwan

Appendix 1. Comparison of size vs. $U_{\text {crit }}$ regression statistics for linear, power and exponential models for each tropical marine fish species tested. $y=$ critical swimming speed, $x=$ standard length (SL)

\begin{tabular}{|lllccccc}
\hline Family & Species & Linear model & $\mathrm{R}^{2}$ & Power model & $\mathrm{R}^{2}$ & Exponential model & $\mathrm{R}^{2}$ \\
\hline Carangidae & Trachinotus blochii & $y=2.515 x-0.775$ & 0.376 & $y=2.107 x^{1.057}$ & 0.369 & $y=3.837 \mathrm{e}^{0.218 x}$ & 0.359 \\
Chanidae & Chanos chanos & $y=2.058 x-9.838$ & 0.487 & $y=0.031 x^{2.469}$ & 0.453 & $y=0.699 \mathrm{e}^{0.252 x}$ & 0.443 \\
Ephippidae & Platax tiera & $y=1.305 x+0.290$ & 0.497 & $y=1.615 x^{0.892}$ & 0.494 & $y=3.639 \mathrm{e}^{0.128 x}$ & 0.493 \\
Leiognathidae & Leiognathus equulus & $y=1.691 x+2.396$ & 0.494 & $y=0.413 x^{1.495}$ & 0.519 & $y=2.219 \mathrm{e}^{0.167 x}$ & 0.471 \\
Lutjanidae & Lutjanus malabaricus & $y=2.269 x-11.128$ & 0.824 & $y=0.071 x^{2.034}$ & 0.600 & $y=1.171 \mathrm{e}^{0.168 x}$ & 0.608 \\
Polynemidae & Elutheronema & $y=1.366 x-1.018$ & 0.611 & $y=0.567 x^{1.306}$ & 0.681 & $y=3.944 \mathrm{e}^{0.104 x}$ & 0.608 \\
& tetradactylum & & & & & & \\
Serranidae & Epinephelus coioides & $y=2.546 x-10.766$ & 0.924 & $y=0.0046 x^{3.250}$ & 0.931 & $y=0.137 \mathrm{e}^{0.356 x}$ & 0.825 \\
Serranidae & Epinephelus & $y=2.197 x-9.700$ & 0.790 & $y=0.416 x^{1.467}$ & 0.783 & $y=7.150 \mathrm{e}^{0.076 x}$ & 0.738 \\
& fuscoguttatus & & & & & & \\
Serranidae & Epinephelus & $y=2.135 x-6.193$ & 0.905 & $y=0.050 x^{2.108}$ & 0.918 & $y=0.299 \mathrm{e}^{0.202 x}$ & 0.934 \\
& malabaricus & & & & & & \\
\hline
\end{tabular}

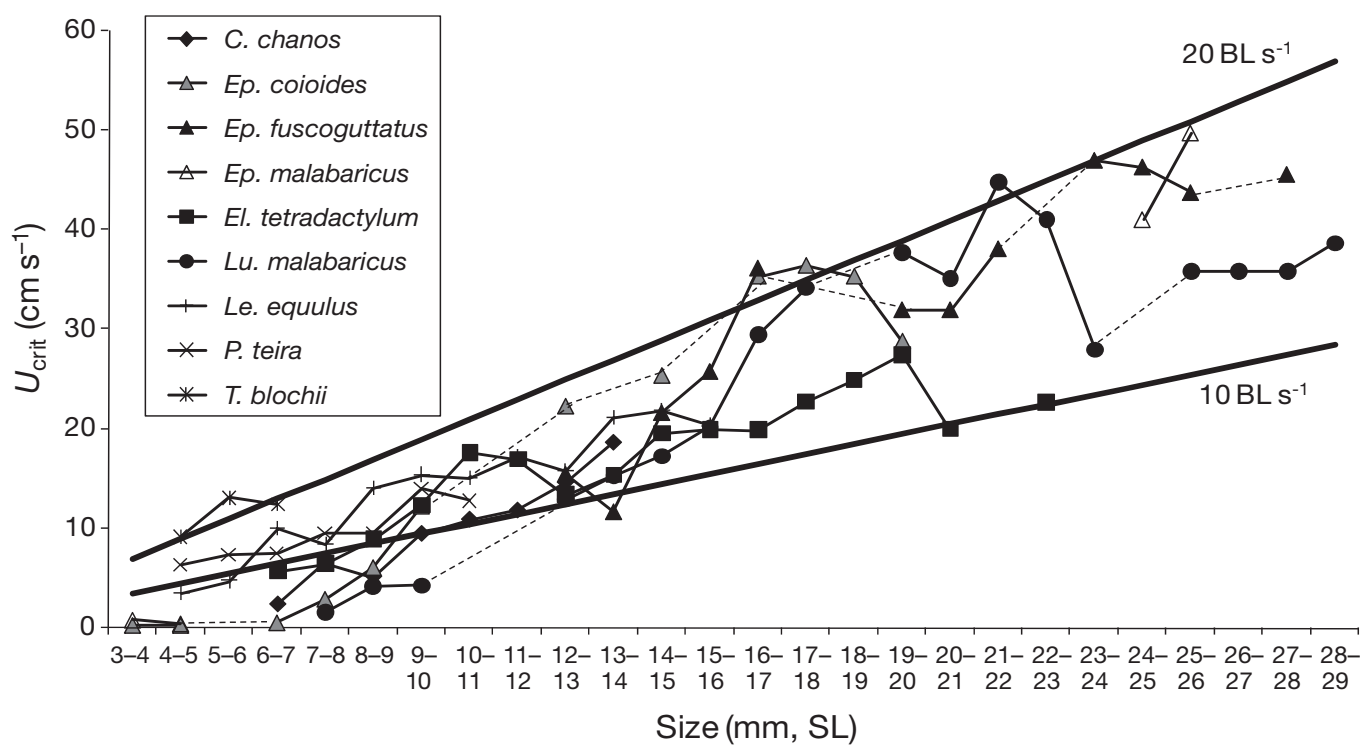

Appendix 2. Ontogeny of $U_{\text {crit }}$ in larvae of 9 species of tropical marine fishes that hatch from pelagic eggs from the present study: Chanos chanos, Epinephelus coioides, Epinephelus fuscoguttatus, Epinephelus malabaricus, Eleuthronema tetradactylum, Lutjanus malabaricus, Leiognathus equulus, Platax teira and Trachinotus blochii. Plotted values are mean $U_{\text {crit }}\left(\mathrm{cm} \mathrm{s}^{-1}\right)$ at $1 \mathrm{~mm}$ increments of standard length (SL). Species represented by symbols of the same shape are in the same family. Dashed lines connect values across intervening size increments for which data are lacking. Note that for Ep. malabaricus, $U_{\text {crit }}$ data were available for only 4 size increments: 3-4, 5-6, 24-25 and 25-26 mm SL

Editorial responsibility: Charles Birkeland (Contributing Editor), Honolulu, Hawaii, USA
Submitted: February 19, 2007; Accepted: June 8, 2007

Proofs received from author(s): October 24, 2007 